\title{
High expression of carbonic anhydrase 12 (CA12) is associated with good prognosis in breast cancer
}

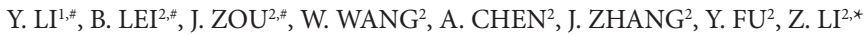 \\ ${ }^{1}$ Department of Oncology, The Second Affiliated Hospital of Harbin Medical University, 246 Xuefu Road, Harbin, China; ${ }^{2}$ Department of Breast \\ Surgery, The Affiliated Tumor Hospital of Harbin Medical University, 150 Haping Road, Harbin, China \\ ${ }^{*}$ Correspondence: drzhigaoli@126.com \\ ${ }^{*}$ Contributed equally to this work.
}

Received August 19, 2018/ Accepted December 5, 2018

\begin{abstract}
The purpose of this research was to explore whether expression of carbonic anhydrase 12 (CA12) and prognosis are significantly related in breast cancer patients. A total of 262 breast cancer specimens and 75 normal breast tissue specimens were used in this study. The expression of CA12 was detected by immunohistochemistry (IHC) and its correlation with the clinicopathological characteristics of breast cancer patients and their prognosis were further analyzed through standard statistical algorithms. The results of immunohistochemical staining showed that CA12 was detected in both normal breast tissue and breast cancer tissue. Compared to normal breast tissue, CA12 was significantly higher expressed in cancer tissues $(\mathrm{p}=0.009)$. Statistical analysis showed that the high expression of CA12 in breast cancer tissue was related to estrogen receptor expression level $(\mathrm{p}<0.001)$. The follow-up of 262 cases of breast cancer patients within 5 years showed that patients with high expression of CA12 had significantly better outcome in DFS $(\mathrm{p}=0.020)$ and OS $(\mathrm{p}=0.019)$ than patients with low expression. Univariate analysis of DFS showed that lymph node metastasis $(\mathrm{p}=0.034)$ and CA12 $(\mathrm{p}=0.024)$ are prognostic indicators. Multivariate analysis manifested that the expression of CA12 $(\mathrm{p}=0.025)$ and lymph node metastasis $(\mathrm{p}=0.024)$ are two independent factors affecting the prognosis of breast cancer. Conclusion: In breast cancer patients, CA12 can be seen as a new prognostic indicator and even a new target for treatment.
\end{abstract}

Key words: breast cancer, CA12, acid microenvironment, clinical pathology

The incidence and mortality of breast cancer in Chinese women's groups are increasing year by year, which seriously endangers women's physical and mental health [1]. Although some great progress have been obtained in breast cancer treatment, but there are still lots of patients with breast cancer suffering relapse and metastasis owing to breast cancer treatment failure, so development of new therapeutic targets and improving prognosis and quality of patients life, has very important clinical significance.

Compared with normal tissues, the tumor tissues always generate extra metabolic products such as lactic acid and carbonic acid. The tumor cells are always in an acidic tumor microenvironment for the accumulation of acidic metabolites. Some study confirmed that the tumor microenvironment of acidification is helpful for tumor recurrence and metastasis [2, 3]. Our previous experiments had found that CA12 was independent of HER-2 expression and may have potential correlation with the prognosis of breast cancer [4]. CA12 is a single transmembrane protease containing zinc metal in family of $\alpha$-carbonic anhydrase, CA12 participates in the biological processes of acid base balance regulation and ion exchange. By catalytic reversible hydration reaction of carbon dioxide, CA12 in tumor tissue can participate in the processes of extracellular microenvironment $\mathrm{pH}$ adjustment and facilitate a weak acidic condition which may cause some bad infects for tumor treatment [5]. As we known, there are few studies focusing on the relation between CA12 and breast cancer prognosis, we discovered its potential importance in our recent study by accident. Different from some scholars by comparing CA12 with other prognostic factors [9], we directly analyzed patients' prognosis and CA12 to find their potential relation. Individualized treatment is a trend except that traditional prognostic factors, we need more massages and data to make an individualized treatment plan. We hope that our research will promote CA12 as a routine prognostic marker to help patients get better individualized treatment. For this purpose, we did the following experiment. 


\section{Materials and methods}

First, we used immunohistochemistry to observe whether the expression level of CA12 in breast cancer tissues and normal tissues were different, and these differences were or not related to the clinical pathology of breast cancer patients. Furthermore, we studied if the expression of CA12 had influence on the five years disease-free survival (DFS) and overall survival (OS) of these patients. For this hypothesis, we further explored whether the effect of CA12 on breast cancer patients is independent.

Subjects. In this experiment, we chose 262 cases of breast cancer tissues and 75 cases of normal breast tissue diagnosed after surgical resection between January 2010 and June 2010 from the Harbin Medical University Affiliated Tumor Hospital Tissue Library. All of the 262 breast cancer specimens were diagnosed as definite breast cancer by two experienced pathologists after surgical operation, and the 75 cases of normal breast tissue applied the same method. All breast tissues were handled as following standard procedures: frozen in liquid nitrogen after resection and convey to our Tissue Library where samples were made into standard slides, then preserved at $-80^{\circ} \mathrm{C}$ for long-term. The most important criteria for inclusion were: no chemotherapy, no radiotherapy, and no endocrine therapy before surgery, primary unilateral breast cancer. All patients had complete clinicopathological information including lymph node metastasis (LNM), age, histology grade, tumor size, estrogen receptor (ER), progesterone receptor (PR), human epidermal growth factor receptor-2 (HER-2), Ki67 and P53. According to the Chinese Guidelines and Specifications of Diagnosis and Treatment of Breast Cancer, all patients received regular treatment after surgery. Follow-up continued at least 5 years or to the death after operation. All patients had signed the relevant informed consent and the Ethics Committee of Harbin Medical University had approved the experimental protocol.

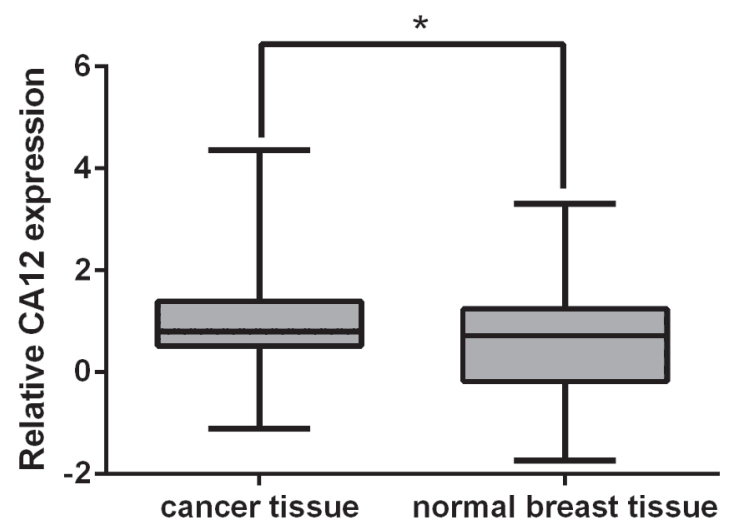

Figure 1. Unpaired t test: Relative expression levels of CA12 in breast cancer tissue and normal breast tissue, the CA12 expression of breast cancer tissue is higher than normal tissue $(\mathrm{p}=0.009)$.
Tissue microarray and immunohistochemistry. Immunohistochemistal staining was implemented by a BechMark XT autostainer (Ventana Medical Systems, Tucson, AZ) employing ani-View detection kit (Ventana Medical Systems) for CA12 (1:10, ab140385, Abcam). The CA12 expression levels were classified based on staining intensity and distribution percentage. According to staining cells color(from no staining to light yellow, yellow-brown and brown), the staining intensity was graded from weak to strong as $0,1,2$, and 3 correspondingly. According to the percentage of staining cells $(0-100 \%)$, no positive tumor cells was graded as 0 , fewer than $10 \%$ positive tumor cells was graded as 1, 10-50\% positive tumor cells was graded as 2 , more than $50 \%$ positive tumor cells was graded as 3 [6]. The last expression score was worked out by multiplying the intensity and distribution values. Product $<4$ was seen as low expression, and the others were high expression. The positive or negative criterion for clinicopathological features as follow: HER-2 only $3+$ was classified as positive; $0,1+$, and $2+$ (depending on FISH result) were negative; histological grade 1 and 2 were regarded as negative, 3 were positive; ER and $\mathrm{PR}$ were regarded as positive if expression rate higher than $10 \%$ (including 10\%) in the invasive component for respectively.

Statistical analysis. All statistical data analysis was performed by SPSS version 17.0. Unpaired $t$ test was performed to analyze the difference of CA12 expression between breast cancer tissues and normal breast tissues (Figure 1) .We analyzed the relationship between CA12 expression levels and clinicopathological features in breast cancer patients by chi-square and t tests. The Kaplan-Meier method were performed to assess the five years OS and DFS of 262 breast cancer patients. Log-rank test was used for univariate analysis. Survival variables were analyzed by Cox multivariate proportional hazards model. A p-value less than 0.05 was considered statistically significant.

\section{Results}

CA12 expression was significantly higher in breast cancer tissue than normal tissue. As shown in Figure 1, in 262 breast cancer tissues and 75 normal breast tissues, we discovered that CA12 expression was obviously higher in breast cancer tissues ( $\mathrm{p}=0.009)$, which was statistically significant. We selected some representative pictures in the process of observing CA12 coloring (Figure 2).

Relation between CA12 expression and clinicopathological features. According to the median value, we set CA12 expression levels as high or low to assess the association between CA12 expression and clinicopathological features. Data analysis showed that the expression of CA12 and ER had a close correlation $(\mathrm{p}<0.001)$. And there were no significant correlation with age, tumor size, LNM, histology grade, and the expression of PR, HER-2, Ki67 and P53. Relevant literature reported $[8,9]$, that the expression of CA12 is 

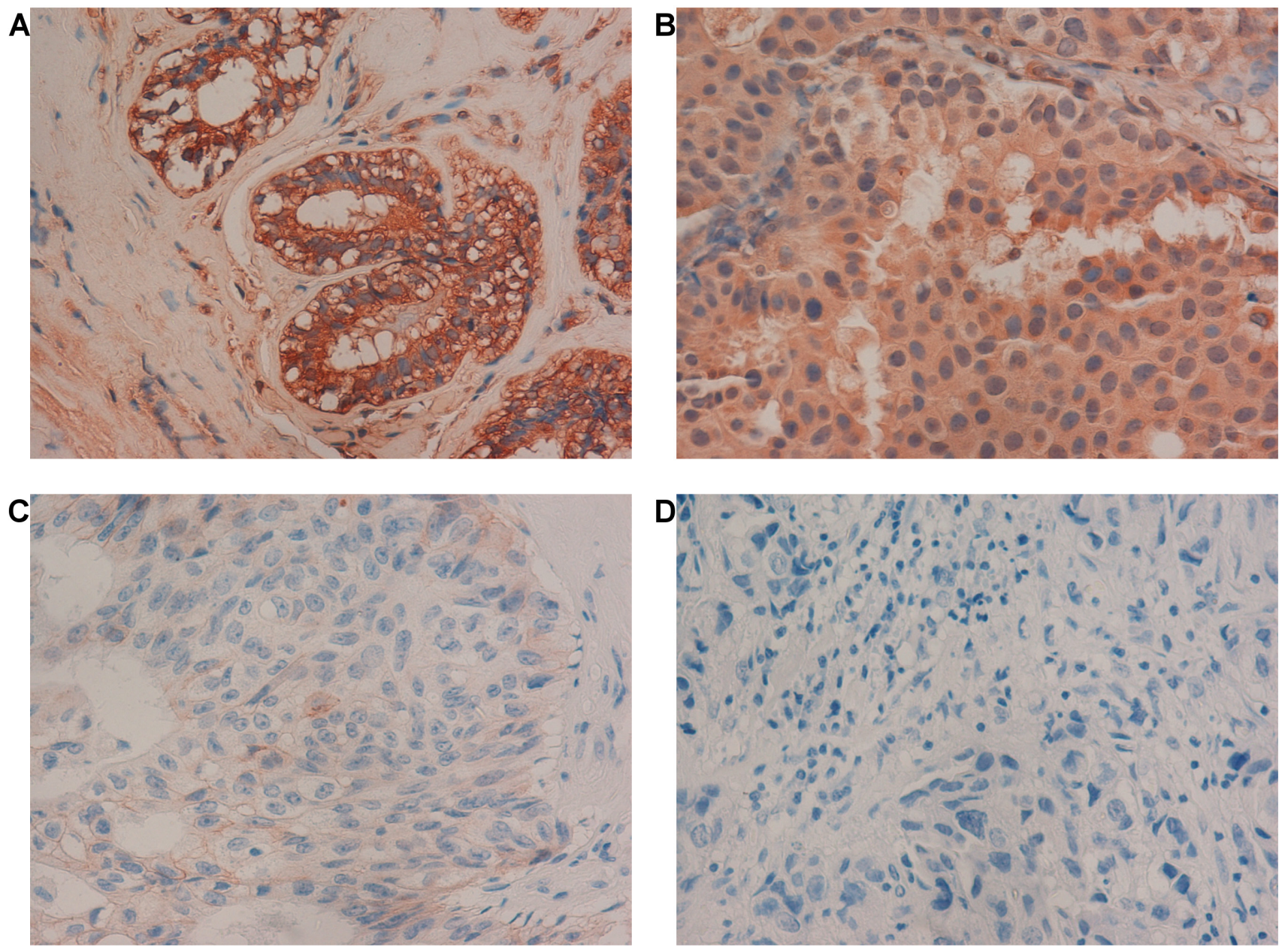

Figure 2. Some representative pictures of the staining cells. A) High expression CA12 of normal breast tissue, strong membranous staining of CA12 is observed $(\times 200)$. B) High expression CA12 of breast cancer tissue, diffuse cytoplasmic staining of CA12 is observed $(\times 200)$. C) Low expression CA12 of breast cancer tissue, the staining color became $\operatorname{dim}(\times 200)$. D) Breast cancer negative control, we hardly find any staining $(\times 100)$.

regulated by ER, which is consistent to the results of this experiment (Table 1).

High CA12 expression is a good prognostic indicator in breast cancer patients. Kaplan-Meier analysis revealed that high CA12 expression in breast cancer patients caused obvious better OS $(\mathrm{p}=0.019)$ and DFS $(\mathrm{p}=0.020)$ within 5 years follow-up (Figure 3). Univariate analysis of DFS showed that only LNM $(p=0.034)$ and CA12 $(p=0.024)$ were prognostic indicators (Table 2). Similarly, univariate analysis of OS demonstrated that LNM $(\mathrm{p}=0.025)$ and CA12 $(\mathrm{p}=0.024)$ were prognostic indicators (Table 3$)$. And the left features including age, tumor size, ER, PR, HER-2, histology grade, Ki67 and $\mathrm{P} 53$ did not have a significant relation with prognostic. In addition, except LNM which is an independent indicator accepted widely for years, the multivariate analysis revealed that the group of high CA12 expression had showed significantly better DFS ( $\mathrm{p}=0.035$; Table 2$)$ and OS $(\mathrm{p}=0.034$; Table 3 ) than the low expression group, so CA1 2 could serve as an important prognostic factor in breast cancer patients independently.

\section{Discussion}

CA12 is a single transmembrane protease located on the cell membrane surface. Just like other members of CA family, CA12 has an important role in catalyzing carbon dioxide hydration which is a reversible reaction. By catalytic reversible hydration reaction of carbon dioxide, CA12 in tumor tissue can participate in the processes of extracellular microenvironment $\mathrm{pH}$ adjustment and facilitate a weak acidic condition which may cause some bad infects for tumor treatment [5]. It has been proven that CA12 is widely expressed in human tumors and normal tissue [7]. Breast cancer is one of the most common malignancy in women and at the same time it is the primary cause of cancer deaths in women. The development of breast cancer is a gradual process. How to 
Table 1. Correlation between CA12 expression and clinicopathological features.

\begin{tabular}{|c|c|c|c|c|}
\hline \multirow{2}{*}{ Variable } & \multirow{2}{*}{$\mathbf{N}$} & \multicolumn{2}{|c|}{ CA12 expression } & \multirow{2}{*}{ p-value } \\
\hline & & Low & High & \\
\hline \multicolumn{5}{|l|}{ Age (years) } \\
\hline$<50$ & 123 & 63 & 60 & \multirow{2}{*}{0.805} \\
\hline$\geq 50$ & 139 & 68 & 71 & \\
\hline \multicolumn{5}{|l|}{ Tumor size } \\
\hline$\leq 2 \mathrm{~cm}$ & 74 & 35 & 39 & \multirow{2}{*}{0.681} \\
\hline$>2 \mathrm{~cm}$ & 188 & 96 & 92 & \\
\hline \multicolumn{5}{|l|}{ LNM } \\
\hline Negative & 119 & 55 & 64 & \multirow{2}{*}{0.321} \\
\hline Positive & 143 & 76 & 67 & \\
\hline \multicolumn{5}{|c|}{ Histology grade } \\
\hline Negative & 202 & 94 & 108 & \multirow{2}{*}{0.055} \\
\hline Positive & 60 & 37 & 23 & \\
\hline \multicolumn{5}{|l|}{ ER } \\
\hline Negative & 111 & 70 & 41 & \multirow{2}{*}{$<0.001$} \\
\hline Positive & 151 & 61 & 90 & \\
\hline \multicolumn{5}{|l|}{ PR } \\
\hline Negative & 177 & 96 & 81 & \multirow{2}{*}{0.064} \\
\hline Positive & 85 & 35 & 50 & \\
\hline \multicolumn{5}{|l|}{ HER2 } \\
\hline Negative & 152 & 77 & 75 & \multirow{2}{*}{0.900} \\
\hline Positive & 110 & 54 & 56 & \\
\hline \multicolumn{5}{|l|}{ Ki67 } \\
\hline$<14 \%$ & 80 & 36 & 44 & \multirow{2}{*}{0.348} \\
\hline$\geq 14 \%$ & 182 & 95 & 87 & \\
\hline \multicolumn{5}{|l|}{ P53 } \\
\hline Negative & 157 & 77 & 82 & \multirow{2}{*}{0.801} \\
\hline Positive & 105 & 54 & 51 & \\
\hline
\end{tabular}

A

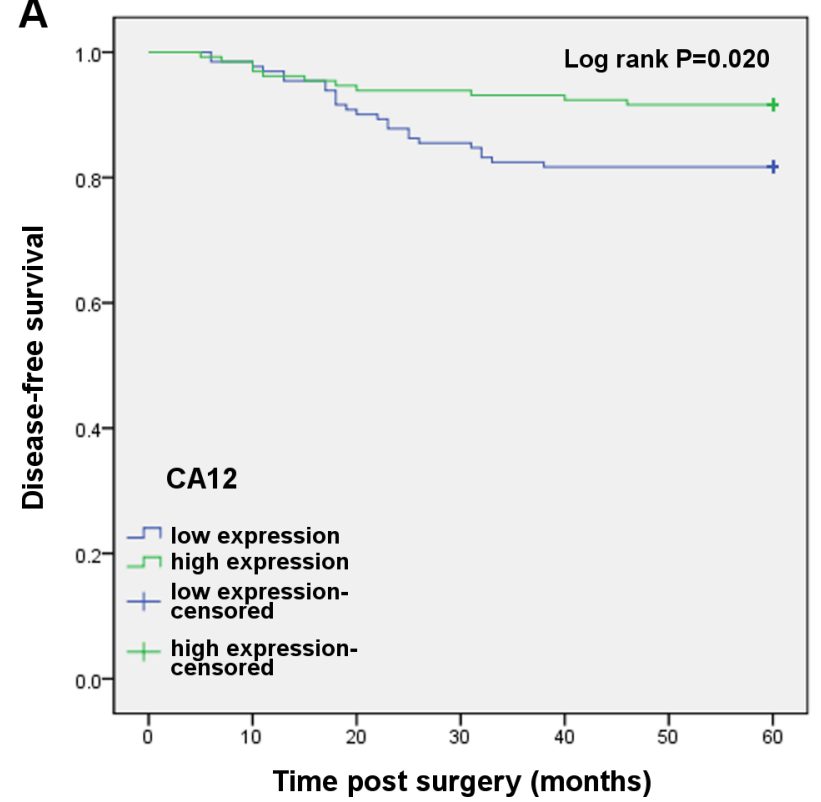

detect breast cancer early, and how to formulate targeted treatment after diagnosis is the primary task for every clinicians. For advanced breast cancer, although modern medicine has made many great progress, chemotherapy is still the main treatment and its effect is not satisfactory. In addition, we found that breast cancer often develops resistance during chemotherapy. Studies have demonstrated that breast cancer progression does not only include tumor cells itself, but also some significant changes in the surrounding matrix or tumor microenvironment. In recent years, these changes have been considered as a key factor in breast cancer metastasis and recurrence, as well as potential therapeutic targets [10]. With the deepening research of tumor microenvironment and drug resistance mechanisms, the importance of tumor acid microenvironment in drugs resistance has gradually been popularized and accepted by scholars. Both the increase of acid metabolites and the increase of transmembrane transport have resulted in tumor acidic microenvironment, which is responsible for the emergence of resistance to chemotherapy drugs [3]. Therefore, the CA12 targeted drugs will provide more options for breast cancer treatment particularly by decreasing drugs resistance.

Although CA12 is widely expressed in many tissues, its expression level varies from tissue to tissue. The CA12 expression in cancer and tumor tissues is higher compared to normal tissues. However, until the date of submission, we did not find any article or experiment that clearly explains the causes and mechanisms of this phenomenon. However, most of the researchers and data support the notion that CA12 is overexpressed in tumor tissues due to hypoxia. And we do believe this conjecture. Because of perfusion deficits,

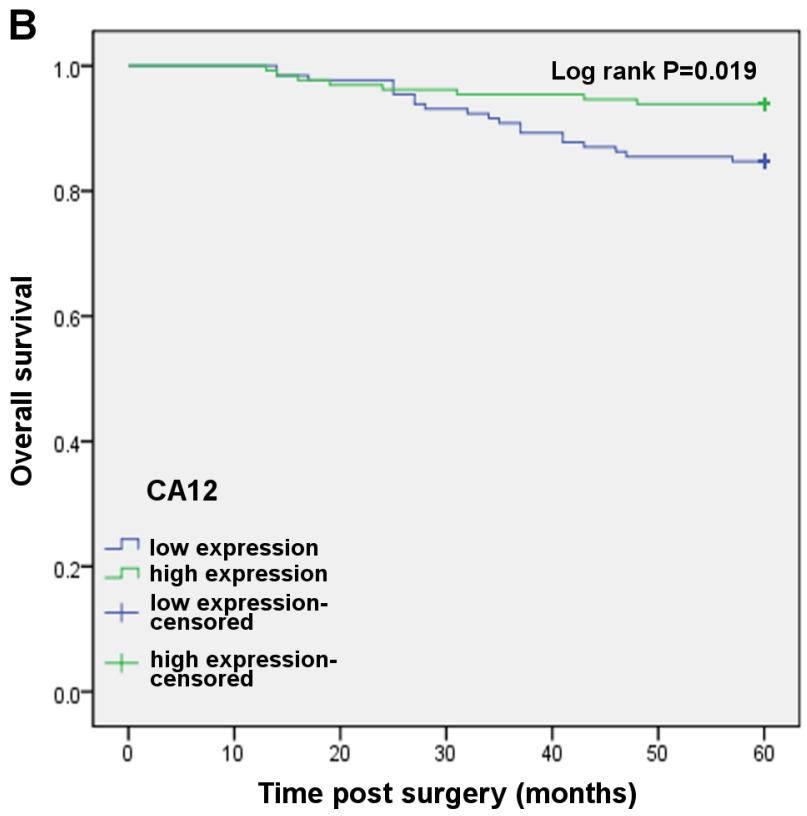

Figure 3. A) 5-years disease-free survival $(\mathrm{p}=0.020)$ and $\mathrm{B}) 5$-years overall survival $(\mathrm{p}=0.019)$ of breast cancer patients based on CA12 expression levels (131 high expression patients and 131 low expression patients). 
Table 2. Cox proportional hazards model of OS in breast cancer patients.

\begin{tabular}{|c|c|c|c|c|c|c|}
\hline \multirow{2}{*}{ Variable } & \multicolumn{3}{|c|}{ Univariate } & \multicolumn{3}{|c|}{ Multivariate } \\
\hline & $\mathbf{R R}$ & $95 \% \mathrm{CI}$ & p-value & RR & $95 \% \mathrm{CI}$ & p-value \\
\hline \multicolumn{7}{|l|}{ Age (years) } \\
\hline$\geq 50 /<50$ & 1.622 & $0.749-3.514$ & 0.220 & & & \\
\hline \multicolumn{7}{|l|}{ Tumor size } \\
\hline$\geq 2 \mathrm{~cm} /<2 \mathrm{~cm}$ & 1.179 & $0.501-2.774$ & 0.705 & & & \\
\hline \multicolumn{7}{|l|}{ LNM } \\
\hline Positive /Negative & 2.662 & $1.132-6.263$ & 0.025 & 2.506 & $1.064-5.904$ & 0.036 \\
\hline \multicolumn{7}{|l|}{ Histology grade } \\
\hline Positive /Negative & 0.744 & $0.283-1.957$ & 0.549 & & & \\
\hline \multicolumn{7}{|l|}{ ER } \\
\hline Positive /Negative & 0.842 & $0.401-1.770$ & 0.650 & & & \\
\hline \multicolumn{7}{|l|}{ PR } \\
\hline Positive /Negative & 0.962 & $0.435-2.127$ & 0.924 & & & \\
\hline \multicolumn{7}{|l|}{ HER2 } \\
\hline Positive / Negative & 1.605 & $0.764-3.373$ & 0.212 & & & \\
\hline \multicolumn{7}{|l|}{ Ki67 } \\
\hline$\geq 14 \% /<14 \%$ & 1.337 & $0.569-3.146$ & 0.505 & & & \\
\hline \multicolumn{7}{|l|}{ P53 } \\
\hline Positive /Negative & 0.965 & $0.452-2.061$ & 0.928 & & & \\
\hline \multicolumn{7}{|l|}{ CA12 } \\
\hline Negative/Positive & 2.578 & $1.135-5.854$ & 0.024 & 2.428 & $1.068-5.520$ & 0.034 \\
\hline
\end{tabular}

Table 3. Cox proportional hazards model of DFS in breast cancer patients.

\begin{tabular}{|c|c|c|c|c|c|c|}
\hline \multirow{2}{*}{ Variable } & \multicolumn{3}{|c|}{ Univariate } & \multicolumn{3}{|c|}{ Multivariate } \\
\hline & RR & $95 \% \mathrm{CI}$ & p-value & RR & $95 \% \mathrm{CI}$ & p-value \\
\hline \multicolumn{7}{|l|}{ Age (years) } \\
\hline$\geq 50 /<50$ & 1.333 & $0.678-2.621$ & 0.405 & & & \\
\hline \multicolumn{7}{|l|}{ Tumor size } \\
\hline$\geq 2 \mathrm{~cm} /<2 \mathrm{~cm}$ & 0.976 & $0.469-2.031$ & 0.947 & & & \\
\hline \multicolumn{7}{|l|}{ LNM } \\
\hline Positive / Negative & 2.213 & $1.063-4.609$ & 0.034 & 2.100 & $1.007-4.378$ & 0.048 \\
\hline \multicolumn{7}{|l|}{ Histology grade } \\
\hline Positive / Negative & 0.858 & $0.375-1.964$ & 0.717 & & & \\
\hline \multicolumn{7}{|l|}{ ER } \\
\hline Positive / Negative & 1.266 & $0.638-2.513$ & 0.501 & & & \\
\hline \multicolumn{7}{|l|}{ PR } \\
\hline Positive / Negative & 1.088 & $0.542-2.187$ & 0.812 & & & \\
\hline \multicolumn{7}{|l|}{ HER2 } \\
\hline Positive / Negative & 1.666 & $0.857-3.240$ & 0.132 & & & \\
\hline \multicolumn{7}{|l|}{ Ki67 } \\
\hline$\geq 14 \% /<14 \%$ & 1.503 & $0.683-3.309$ & 0.311 & & & \\
\hline \multicolumn{7}{|l|}{ P53 } \\
\hline Positive / Negative & 0.760 & $0.378-1.528$ & 0.442 & & & \\
\hline \multicolumn{7}{|l|}{ CA12 } \\
\hline Negative/Positive & 2.270 & $1.112-4.635$ & 0.024 & 2.161 & $1.057-4.418$ & 0.035 \\
\hline
\end{tabular}

some regions inside tumors become anoxic and consequently hypoxia induces CA12 expression. Besides, hypoxia promotes an acidic environment. In tumors, acidic environment has been demonstrated to facilitate cell proliferation and tumor growth [21]. It has been proposed that exposure to chronic acidosis may facilitate cancer cell clonal evolution by inducing chromosomal instability, clastogenicity, and gene mutations. In addition, acidosis may contribute to metastatic progression by degrading the extracellular matrix [3]. CA12 was first detected by serological screening of human renal cell 
carcinoma. Overexpression of wild type von Hippel Lindau (VHL) in cancer cell lines reduced the CA12 overexpression, while overexpression of mutant VHL enhanced the CA12 expression $[11,12]$. In all renal carcinoma, CA12 expression is principally seen in transparent cell carcinoma. And in this carcinoma, the expression level of CA12 has a significant relation to tumor histological classification [13]. Some scholars investigated 70 cases of esophageal cancer patients by using immunohistochemistry to elaborate the relationship between CA12 expression and clinicopathological features and prognosis. They found that the CA12 expression could be a valuable prognostic factor for patients with advanced esophageal squamous cell carcinoma (ESCC). Their results promoted CA12 to be seen as an indicator in ESCC [14]. Recent studies found that high expression of CA12 arises in colorectal cancer [15], cervical cancer [16] and lung cancer [17] and some other tumor tissues. In our experiments, we found that CA12 was highly expressed in breast cancer tissues compared to normal breast tissue and this difference was statistically significant $(p=0.009)$. We believe that the reason for this was the anaerobic environment of tumor tissues which promotes high expression of CA12, and the related drug experiments showed the same outcome as was our conjecture [18]. Some experimental results show that the higher is the expression level of CA12 in breast cancer, the lower is the tumor histological grading and malignant degree, while tumor cell differentiation is better, relapse and metastasis risk are lower and the prognosis is better $[19,20]$.

Our clinical pathology data analysis revealed a close correlation between CA12 expression and estrogen receptor $(\mathrm{p}<0.001$, Table 1) in 262 breast cancer patients. Some previous studies suggested an important role of ER in CA12 expression and our findings are consistent with the results of these studies $[3,8]$. Therefore, herein we propose an explanation of why CA12 should be seen as a good prognostic factor while it promotes low $\mathrm{PH}$ microenvironment which has been claimed to cause negative effects, including resistance to chemotherapeutic drugs, tumor recurrence, and so on [3, 22]. Our article and others have found that CA12 is closely related to ER, and the expression of ER is a good prognostic marker because of endocrine intervention. Our experiments were conducted without affecting the patient's treatment. In other words, all patients in need of endocrine therapy (ER and/or PR positive) had received standard endocrine therapy. Endocrine therapy plays an important and positive role in breast cancer patient prognosis. Therefore, taken together, we think that CA12 has more positive than negative effect on prognosis in breast cancer. However, this is a corollary, and a great deal of subsequent experiments and work are needed to study its detailed mechanism.

This study found that breast cancer patients with high expression of CA12 had better DFS ( $p=0.020$, Figure $3 \mathrm{~A}$ ) and $\mathrm{OS}(\mathrm{p}=0.019$, Figure $3 \mathrm{~B})$ than those in low expression group. According to clinicopathological data and CA12 expression, COX risk assessment for breast cancer patients found that lymph node metastasis ( $\mathrm{p}=0.048, \mathrm{p}=0.036$, respectively in DSF and OS) and CA12 expression ( $\mathrm{p}=0.035$, $\mathrm{p}=0.034$, respectively in DSF and OS) were two independent prognostic factors. Therefore, CA12 not only can be seen as an independent indicator for breast cancer prognosis, but may also be used as a new target for breast cancer treatment.

CA12 was discovered in a variety of tumor tissues, but there are only few studies of breast cancer tissue. Combined with clinicopathological features, the influence of CA12 on breast cancer prognosis is the highlight of this experiment. Some shortcomings of our experiments were that CA12 had not associated with hypoxia induced and blood vessels of experimental study, and no control CA12 lack upstream gene sequences to verify CA12 genes related to occurrence and development of tumor. Besides, all samples were taken from the same institution and sample size was not large enough, which could lead to some unavoidable deviations. However, what we are interested in is how important is the role CA12 plays in living animal experiments as a new target, and whether CA12 can be used as a clinical prognostic indicator.

Acknowledgments: The study was supported by the grant of Heilongjiang Postdoctoral Financial Assistance (LBH-Z16104 and LBH-Z17111), The Fundamental Research Funds for the Provincial Universities (2017LCZX73) and The Health and Family Planning Commission Research Project of Heilongjiang Province (2018252).

\section{References}

[1] CHEN W, ZHENG R, ZUO T, ZENG H, ZHANG S et al. National cancer incidence and mortality in China, 2012. Chin J Cancer Res 2016; 28: 1-11. https://doi.org/10.3978/j. issn.1000-9604.2016.02.08

[2] STRANSKY L, COTTER K, FORGAC M. The Function of V-ATPases in Cancer. Physiol Rev 2016; 96: 1071-1091. https://doi.org/10.1152/physrev.00035.2015

[3] JUSTUS CR, DONG L, YANG LV. Acidic tumor microenvironment and $\mathrm{pH}$-sensing $\mathrm{G}$ protein-coupled receptors. Front Physiol 2013; 4: 354. https://doi.org/10.3389/ fphys.2013.00354

[4] LEI B, ZHANG XY, ZHOU JP, MU GN, LI YW et al. Transcriptome sequencing of HER2-positive breast cancer stem cells identifies potential prognostic marker. Tumour Biol 2016; 37: 14757-14764. https://doi.org/10.1007/s13277-0165351-0

[5] WAHEED A, SLY WS. Carbonic anhydrase XII functions in health and disease. Gene 2017; 623: 33-40. https://doi. org/10.1016/j.gene.2017.04.027

[6] Remmele W, Stegner HE. [Recommendation for uniform definition of an immunoreactive score (IRS) for immunohistochemical estrogen receptor detection (ER-ICA) in breast cancer tissue]. Pathologe 1987; 8: 138-140.

[7] IVANOV S, LIAO SY, IVANOVA A, DANILKOVITCHMIAGKOVA A, TARASOVA N et al. Expression of hypoxiainducible cell-surface transmembrane carbonic anhydrases in human cancer. Am J Pathol 2001; 158: 905-919. https:// doi.org/10.1016/S0002-9440(10)64038-2 
[8] BARNETT DH, SHENG S, CHARN TH, WAHEED A, SLY WS et al. Estrogen receptor regulation of carbonic anhydrase XII through a distal enhancer in breast cancer. Cancer Res 2008,1; 68: 3505-3515. https://doi.org/10.1158/0008-5472. CAN-07-6151

[9] EOM KY, JANG MH, PARK SY, KANG EY, KIM SW et al. The Expression of Carbonic Anhydrase (CA) IX/XII and Lymph Node Metastasis in Early Breast Cancer. Cancer Res Treat 2016; 48: 125-132. https://doi.org/10.4143/ crt.2014.243

[10] SOYSAL SD, TZANKOV A, MUENST SE. Role of the Tumor Microenvironment in Breast cancer. Pathobiology 2015; 82 (3-4): 142-152. https://doi.org/10.1159/000430499

[11] TURECI O, SAHIN U, VOLLMAR E, SIEMER S, GOTTERT E et al. Human carbonic anhydrase XII: cDNA cloning, expression, and chromosomal localization of a carbonic anhydrase gene that is overexpressed in some renal cell cancers. Proc Natl Acad Sci U S A 1998; 95: 7608-7613. https:// doi.org/10.1073/pnas.95.13.7608

[12] IVANOV SV, KUZMIN I, WEI MH, PACK S, GEIL L et al. Down-regulation of transmembrane carbonic anhydrases in renal cell carcinoma cell lines by wild-type von Hippel-Lindau transgenes. Proc Natl Acad Sci U S A 1998; 95: 1259612601. https://doi.org/10.1073/pnas.95.21.12596

[13] PARKKILA S, PARKKILA AK, SAARNIO J, KIVELA J, KARTTUNEN TJ et al. Expression of the membrane-associated carbonic anhydrase isozyme XII in the human kidney and renal tumors. J Histochem Cytochem 2000; 48: 16011608. https://doi.org/10.1177/002215540004801203

[14] OCHI F, SHIOZAKI A, ICHIKAWA D, FUJIWARA H, NAKASHIMA S et al.Carbonic Anhydrase XII as an Independent Prognostic Factor in Advanced Esophageal Squamous Cell Carcinoma. J Cancer 2015; 6: 922-929. https://doi. org/10.7150/jca.11269
[15] VIIKILA P, KIVELA AJ, MUSTONEN H1, KOSKENSALO S1, WAHEED A et al. Carbonic anhydrase enzymes II, VII, IX and XII in colorectal carcinomas. World J Gastroenterol 2016; 22: 8168-8177. https://doi.org/10.3748/wjg.v22.i36.8168

[16] YOO CW, NAM BH, KIM JY, SHIN HJ, LIM H et al. Carbonic anhydrase XII expression is associated with histologic grade of cervical cancer and superior radiotherapy outcome. Radiat Oncol 2010, 5: 101. https://doi.org/10.1186/1748717X-5-101

[17] KOBAYASHI M, MATSUMOTO T, RYUGE S, YANAGITA $\mathrm{K}$, NAGASHIO $\mathrm{R}$ et al. CAXII Is a sero-diagnostic marker for lung cancer. PLoS One 2012; 7: e33952. https://doi. org/10.1371/journal.pone.0033952

[18] GULER OO, DE SIMONE G, SUPURAN CT. Drug design studies of the novel antitumor targets carbonic anhydrase IX and XII. Curr Med Chem 2010; 17: 1516-1526. https://doi. org/10.2174/092986710790979999

[19] WYKOFF CC, BEASLEY N, WATSON PH, CAMPO L, CHIA SK et al. Expression of the hypoxia-inducible and tumor-associated carbonic anhydrases in ductal carcinoma in situ of the breast. Am J Pathol 2001; 158: 1011-1019. https:// doi.org/10.1016/S0002-9440(10)64048-5

[20] WATSON PH, CHIA SK, WYKOFF CC, HAN C, LEEK RD et al. Carbonic anhydrase XII is a marker of good prognosis in invasive breast carcinoma. Br J Cancer 2003; 88: 10651070. https://doi.org/10.1038/sj.bjc.6600796

[21] WEBB BA, CHIMENTI M, JACOBSON MP, BARBER DL. Dysregulated $\mathrm{pH}$ : a perfect storm for cancer progression.[J]. Nat Rev Cancer 2011; 11: 671-677. https://doi.org/10.1038/ nrc3110

[22] LIU R, LV QL, YU J, HU L, ZHANG LH et al. Correlating transcriptional networks with pathological complete response following neoadjuvant chemotherapy for breast cancer. Breast Cancer Res Treat 2015; 151: 607-618. https://doi. org/10.1007/s10549-015-3428-X 